\title{
WATER SOLUTION POLISHING OF NITRATE USING POTASSIUM PERMANGANATE MODIFIED ZEOLITE: PARAMETRIC EXPERIMENTS, KINETICS AND EQUILIBRIUM ANALYSIS
}

\author{
MOHSENIBANDPEI A. ${ }^{1}$ \\ GHADERPOORI M. ${ }^{2}$ \\ HASSANI G. ${ }^{3,4}$ \\ BAHRAMI H. ${ }^{5}$ \\ BAHMANI $Z^{6}$ \\ ALINEJAD A.A. ${ }^{5 *}$
}

\author{
${ }^{1}$ Environmental and Occupational Hazards Control Research Center Shahid \\ Beheshti University of Medical Sciences, Tehran, Iran \\ ${ }^{2}$ Students Research committee \\ Department of Environmental Health Engineering \\ Shahid Beheshti University of Medical Sciences, Tehran, Iran \\ ${ }^{3}$ Social Determinants of Health Research Center \\ Yasuj University of Medical Sciences, Yasuj, Iran \\ ${ }^{4}$ Department of Environmental Health Engineering, Faculty of Health \\ Yasuj University of Medical Sciences, Yasuj, Iran \\ ${ }^{5}$ Department of Environmental Health Engineering, School of Public Health \\ Shahid Beheshti University of Medical Sciences, Tehran, Iran \\ ${ }^{6}$ Social Determinants in Health Promotion Research Center \\ Hormozgan University of Medical Sciences, Bandar Abbas, Iran
}

Received: $13 / 11 / 2015$

Accepted: 29/02/2016

Available online: 03/06/2016 *to whom all correspondence should be addressed: e-mail: azimalinejad@gmail.com

\begin{abstract}
In the present study, adsorption potential of potassium permanganate (Hypermangan) modified zeolite was investigated for the removal of nitrate from synthetic wastewater. Effects of the most significant parameters $(\mathrm{pH}$, adsorbent dose, nitrate concentration and contact time) were initially evaluated based on the percentage of nitrate removed from the water solutions. Over $90 \%$ removal of $150 \mathrm{mg} \mathrm{l}^{-1}$ nitrate was achieved at an optimum pH of 5, adsorbent dose of $2 \mathrm{~g}^{-1}$ after a 60 min contact time. The chemical and morphological characterizations of Hypermangan modified zeolite ( $\mathrm{HMZ})$ were carried out by using scanning electron microscopy (SEM), fourier transform infrared (FT-IR), x-ray diffraction (XRD) and x-ray fluorescence (XRF) analysis methods. Kinetic evaluation indicated that the nitrate adsorption onto $\mathrm{HMZ}$ followed the pseudofirst-order model. The equilibrium data assessment illustrated the removal of nitrate by HMZ follows a Langmuir model which attains the maximum adsorption capacity $6.7 \mathrm{mg} \mathrm{g}^{-1}$. The mean free energy of adsorption was $0.15 \mathrm{~kJ} \mathrm{~mol}^{-1}$, which indicates the adsorption of nitrate onto $\mathrm{HMZ}$, occurs through a physical mechanism.
\end{abstract}

Keywords: Hypermangan, Nitrate, Adsorption, Equilibrium, Kinetic

\section{Introduction}

Pollution of water resources by nitrate occurs due to industrial wastewater containing nitrate, domestic wastewater, fertilizers in agricultural, discharges from animal operations, wastewater treatment facilities,

Mohsenibandpei A., Ghaderpoori M., Hassani G., Bahrami H., Bahmani Z. and Alinejad A.A. (2016), Water solution polishing of nitrate using potassium permanganate modified zeolite: Parametric experiments, kinetics and equilibrium analysis, Global NEST Journal, 18(3), 546-558. 
septic systems and commercial activities (Benyoucef et al., 2013; Cheikh et al., 2013). It causes eutrophication problems of rivers, lakes and seas, destroys water quality and presents potential hazards on human health. The WHO guideline value for nitrate is $50 \mathrm{mg} \mathrm{l}^{-1}$ (Cheikh et al., 2013). It needs to be regulated in water basically because excess levels of nitrate effects on health by forming methemoglobinoma in children, hypertension, thyroid disability and carcinogenicity hazard of nitrosamine (Benyoucef et al., 2013). Current nitrate removal techniques include ion exchange, biological denitrification, chemical treatment, reverse osmosis, electrodialysis, catalytic denitrification, membrane filtration, electrocoagulation and adsorption (Zhang et al., 2009; Malekian et al., 2011; Montalvo et al., 2011; Andalib et al., 2012; Rezakazemi et al., 2012; Bravo et al., 2013; Jiang et al., 2013; Yu et al., 2013). Among these methods, adsorption is generally considered to be a simple and efficient method for the removal of nitrate. With the advancement of nanotechnology, attempts have been made in the use of zeolites and their modification form such as hydrated aluminosilicate materials, bentonite and kaoline due to their low cost and availability in large amounts on the earth (Dong et al., 2010; Gupta et al., 2011). Nowadays because of the low cost and simplicity adsorbents such as natural and synthetic zeolite modified, activated carbon fibers and polymeric adsorbents are employed for sorption of pollutants (Gupta and Bhattacharyya, 2008; Hajdu et al., 2012). Lately, several modification methods including hypermangan modification, iron modification, and lanthanum modification have attracted more notice due to improve the zeolite performance, e.g., adsorption capacity and increased mechanical, resistance to chemical environment, physical and chemical properties, high specific surface (surface to volume ratio) and high absorption efficiency. Therefore, in recent times, the interest in new type hypermangan-modified adsorbents is increasing with each passing day (Han et al., 2006a; Han et al., 2006b; Zou et al., 2006; Al Ghouti et al., 2009). In this study hypermangan modification is used due to microporous structure, high specific surface, high absorption efficiency, and lack of penetration resistance due to the elimination of the interior absorption surfaces in porous adsorbent, the possibility to modify and adjust the surface properties of hypermangan. The use of hypermangan adsorbent in form of powder has practical limitations, such as hardness solid/liquid separation, high pressure drop and leaching of metal/metal oxide in final treated water. Thus, to overcome these problems, hypermangan can be coated on zeolite surface to provide an effective adsorbent for nitrate removal from water. It appears that this method provides an effective surface and may increase the pollutants removal from water. The purpose of this study was to construct $\mathrm{HMZ}$, for polishing of water solutions content nitrate that was carried out in batch laboratory system. The nitrate adsorption feasibility onto $\mathrm{HMZ}$ was examined by evaluating the effects of various operating conditions such as $(\mathrm{pH}$, adsorbent dose, nitrate concentration and contact time). The chemical and morphological characterizations of $\mathrm{HMZ}$ were carried out by using SEM, FT-IR, XRD and XRF analysis methods.

\subsection{Materials and methods}

\subsubsection{Materials}

The natural zeolite with a grain size range 1-5 $\mathrm{mm}$, supplied by a company in Semnan province, Iran. The chemical composition of Semnan zeolite is listed as follows, in mass \%: $\mathrm{MnO}=0.04, \mathrm{P}_{2} \mathrm{O}_{5}=0.01, \mathrm{SiO}_{2}=66.5$, $\mathrm{Al}_{2} \mathrm{O}_{3}=11.81, \mathrm{Na}_{2} \mathrm{O}=2.01, \mathrm{CaO}=3.11, \mathrm{MgO}=0.72, \mathrm{~K}_{2} \mathrm{O}=3.12, \mathrm{Fe}_{2} \mathrm{O}_{3}=1.3, \mathrm{TiO}_{2}=0.21$ and loss of ignition (LOI) $=12.05$ that were determined by XRF analysis. Prior to use, the natural zeolite was crushed and sieved to the average particle diameter. Then it was soaked in tap water for $24 \mathrm{~h}$ to decrease its alkaliessence. Potassium permanganate (Sigma-Aldrich, USA) and $\mathrm{HCl}$ (Merck) were used to prepare the $\mathrm{HMZ}$. A stock solution was prepared with dissolving $1.0 \mathrm{~g}$ of analytical grade potassium nitrate $\left(\mathrm{KNO}_{3}\right)$ in $1000 \mathrm{~mL}$ deionized water.

\subsubsection{Preparation of potassium permanganate modified zeolite}

In preparation for surface coating, zeolite sample was washed with deionized water and dried at $373^{\circ} \mathrm{K}$ in the oven. The chemical precipitation used to make HMZ. The zeolite was converted to its $\mathrm{Na}$ form by suspending $50 \mathrm{~g}$ into $500 \mathrm{ml}$ of a $2 \mathrm{M} \mathrm{NaCl}$ solution for a period of $24 \mathrm{~h}$. Then zeolite was washed with deionized water to remove chloride ions, and dried at room temperature. The zeolite was placed in beaker and a boiling solution 
containing potassium permanganate was added into beaker over zeolite. The hydrochloric acid was added into beaker and the solution was mixed at $90^{\circ} \mathrm{C}$ for 1 hours. The media was separated, washed with deionized water and dried at room temperature. It was stored in a polypropylene bottle for further use.

\subsection{Characterization of Adsorbent}

The powder $\mathrm{x}$-ray diffraction (PXRD) technique using (PANalytical 3040/60 X, Pert PRO) with Cu Ka radiation source over a range of $10-60 \mathrm{~nm}$ at a scan speed $1 \mathrm{~s} / \mathrm{step}, 1.54 \AA$ wavelength and $25^{\circ} \mathrm{C}$, was used to measure the crystallinity of samples and compound formation. Diffraction peaks were used to identify the structure of samples by matching their observed patterns with the standard pattern of zeolite (ICDD ASCII card No (01087-2334)).Chemical composition of zeolite was measured by a Shimadzu XRF-1800 with Rh radiation. The Scanning electron micrograph (SEM) (Hitachi S-3000N, Japan) was applied to analyze the morphological structure and topological presentation of $\mathrm{HMZ}$.

FTIR analysis was conducted in a WQF-510A/520A FTIR Spectrometer; the samples were prepared using the $\mathrm{KBr}$ pressed disk technique, with $1 \%$ inclusions of the sample to be analyzed. The zero point of charge for adsorbent was determined to investigate the surface charge of adsorbent material. To determine of $\mathrm{pH}_{\mathrm{zpc}}, 50$ $\mathrm{mL}$ of potassium nitrate $(0.01 \mathrm{M})$ solution was added to Erlenmeyer flasks. Initial solution $\mathrm{pH}$ was adjusted between 2 to 12 by addition of $\mathrm{HCl}$ and $\mathrm{NaOH}$. Then $0.2 \mathrm{~g}$ of adsorbent was added to the Erlenmeyer flasks and mixed for $24 \mathrm{~h}$. Final $\mathrm{pH}$ of solution was measured by using a pH meter (model 50-pp-sartorious). Curve of initial $\mathrm{pH}$ versus final $\mathrm{pH}$ was plotted and the intersection point of curves was recorded as $\mathrm{pH}_{\mathrm{ZPC}}$ (Ngah \& Hanafiah 2008).The specific surface area (based on the BET method) and pore volume were determined by nitrogen gas adsorption analyzer (Micromeretics/Gemini-2372).

\subsection{Experimental procedure}

Batch experiments were carried out in conical flasks containing a definite volume ( $100 \mathrm{ml}$ in each case) with a magnetic stirrer using a constant speed of $200 \mathrm{rpm}$. Stock solution of nitrate $\left(1000 \mathrm{mg} \mathrm{l}^{-1}\right)$ was prepared and the desired concentrations of nitrate were obtained by diluting the stock solution. Table 1 presents experimental runs and conditions. For each experiment, $100 \mathrm{ml}$ nitrate solution was added to the flask, and the test conditions were adjusted to the designated level (Table 1).

Table 1. Experimental runs and conditions for nitrate adsorption onto HMZ.

\begin{tabular}{cccccc}
\hline \multirow{2}{*}{ Run } & Condition & $\mathbf{p H}$ & $\begin{array}{c}\text { Nitrate concentration } \\
\left(\mathbf{m g ~ l}^{-\mathbf{1}} \mathbf{)}\right.\end{array}$ & $\begin{array}{c}\text { HMZ dosage } \\
\text { (g l-1 })\end{array}$ & $\begin{array}{c}\text { Contact time } \\
\text { (min) }\end{array}$ \\
\hline $\mathbf{1}$ & The effect of $\mathrm{pH}$ & $2-11$ & 150 & 2 & 60 \\
\hline $\mathbf{2}$ & The effect of HMZ dosage & 5 & 150 & $0.1-2.5$ & 60 \\
\hline $\mathbf{3}$ & The effect of contact time & 5 & 150 & 2 & $3-100$ \\
\hline $\mathbf{4}$ & Equilibrium tests & 5 & $100-300$ & 2 & 60 \\
\hline
\end{tabular}

After a certain period of time, solid-liquid separation was achieved by centrifugation at $3000 \mathrm{rpm}$ (for $3 \mathrm{~min}$ ). The final concentration of nitrate in the clear solution was determined according to method mentioned in the Standard Method at $220 \mathrm{~nm}$, using a TU-1901 UV/vis spectrophotometer (Beijing Purkinje General Instrument Co., Ltd., China) (APHA, 2005). Each experiment was conducted three times.

\subsection{Kinetic and isotherm analysis}

To evaluate the isotherm models, $2 \mathrm{~g} \mathrm{HMZ}$ was stirred in $100 \mathrm{~mL}$ of different concentrations of the solution (100-300 $\left.\mathrm{mg} \mathrm{l}^{-1}\right)$ at a $\mathrm{pH}$ of 5 for $60 \mathrm{~min}$. In this study, the adsorption of nitrate from its aqueous solution by $\mathrm{HMZ}$ was investigated with four of the most used isotherm models (Langmuir, Freundlich, Temkin and (DR)).The Langmuir, Freundlich, Temkin and D-R isotherm equations are stated as Eqs. 1-4: 


$$
\begin{aligned}
& \frac{c_{e}}{q_{e}}=\frac{1}{q_{m} b}+\frac{1}{q_{m}} c_{e} \\
& \log q_{e}=\log k_{f}+\frac{1}{n} \log c_{e} \\
& q_{e}=B \ln K_{t}+B \ln C_{e} \\
& \ln q_{e}=\ln q_{m}-K_{D R} \varepsilon^{2}
\end{aligned}
$$

Where $\mathrm{C}_{\mathrm{e}}$ is the equilibrium concentration of adsorbate in solution [mg $\mathrm{I}^{-1}$ ], $\mathrm{q}_{\mathrm{e}}$ is the amount adsorbed of equilibrium [ $\mathrm{mg} \mathrm{g}^{-1}$ ] $\mathrm{q}_{\mathrm{m}}$ [the amount of ultimate adsorption capacity [ $\mathrm{mg} \mathrm{g}^{-1}$ ]] and $b$ [energy of adsorption $\left[\mathrm{mg}^{-1}\right]$ are the Langmuir constants that can be calculated from the slope and intercept of the linear plot of $C_{e}$ versus $\mathrm{C}_{\mathrm{e}} / \mathrm{q}_{\mathrm{e}}$ respectively. $\mathrm{K}_{\mathrm{f}}$ and $1 / \mathrm{n}$ are the Freundlich constants related to adsorption capacity and adsorption intensity respectively, that can be obtained from the intercept and slope the linear plot of log $q_{e}$ versus $\log \mathrm{C}_{\mathrm{e}}$. For a favorable adsorption $\mathrm{n}$ should have values lying in the range of 0 to $1 . \mathrm{K}_{\mathrm{t}}$ is the equilibrium binding constant $\left[\mathrm{I} \mathrm{mg}^{-1}\right]$ and $\mathrm{B}$ is the variation of adsorption energy [ $\left[\mathrm{KJ} \mathrm{mol}^{-1}\right], \mathrm{K}_{\mathrm{t}}$ and $\mathrm{B}$ can be calculated from the slope and intercept the linear plot of $q_{e}$ versus $I_{n} c_{e} K_{D R}$ is a constant related to mean free energy of sorption per mol of the sorbate $\left[\mathrm{mg}^{2} \mathrm{~kJ}^{-2}\right]$ and $\varepsilon$ is Polanyi potential $\left[\mathrm{J} \mathrm{mg}^{-1}\right.$. $\mathrm{K}_{\mathrm{DR}}$ can be calculated from the slope of the linear plot of $\ln q_{\mathrm{e}}$ versus $\varepsilon^{2}$. Also $\varepsilon$ can be obtained using following equation:

$$
\varepsilon=\operatorname{RT} \ln \left(1+\frac{1}{C_{e}}\right)
$$

Where $\mathrm{R}$ is the universal gas constant $\left[8.314 \mathrm{KJ} / \mathrm{kmol}{ }^{\circ} \mathrm{K}\right]$ and $\mathrm{T}\left[{ }^{\circ} \mathrm{K}\right]$ is the absolute temperature (Khorramfar et al., 2009). The essential characteristics of Langmuir isotherm, commonly known as the separation factor or equilibrium parameter $\left(R_{L}\right)$ is presented in Eq. (7).

$$
\mathrm{R}_{\mathrm{L}}=\frac{1}{\left[1+\mathrm{b} \mathrm{C}_{0}\right]}
$$

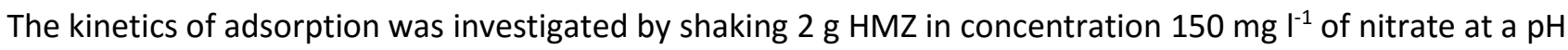
of 5 and varying contact times (5-60 min). Adsorption kinetics of Pseudo-first order, Pseudo-second order, Elovich and Intra particle diffusion have been investigated using following equations:

$$
\begin{aligned}
& \log \left(\mathrm{q}_{\mathrm{e}}-\mathrm{q}_{\mathrm{t}}\right)=\log \mathrm{q}_{\mathrm{e}}-\frac{\mathrm{k}_{1}}{2.303} \mathrm{t} \\
& \frac{\mathrm{t}}{\mathrm{q}_{\mathrm{t}}}=\frac{1}{\mathrm{k}_{2} \mathrm{q}_{\mathrm{e}}^{2}}+\frac{1}{\mathrm{q}_{\mathrm{e}}} \mathrm{t} \\
& \mathrm{q}_{\mathrm{t}}=\left(\frac{1}{\beta}\right) \ln (\alpha \beta)+\left(\frac{1}{\beta}\right) \ln \mathrm{t} \\
& \mathrm{q}_{\mathrm{t}}=\mathrm{k}_{\mathrm{d}} \mathrm{t}^{1 / 2}+\mathrm{l}
\end{aligned}
$$

where $\mathrm{q}_{\mathrm{e}}\left[\mathrm{mg} \mathrm{g}^{-1}\right]$ and $\mathrm{q}_{\mathrm{t}}$ refer to the amounts of adsorption at the equilibrium and any time $\mathrm{t}$ [min] respectively, $\mathrm{k}_{1}\left[\mathrm{~min}^{-1}\right]$ and $\mathrm{k}_{2}$ [g $\left.\mathrm{gg}^{-1} \mathrm{~min}^{-1}\right]$ are the adsorption rate constants in the Pseudo-first order adsorption and Pseudo-second order adsorption respectively, $\mathrm{k}_{1}\left[\mathrm{~min}^{-1}\right]$ can be calculated from the slope of

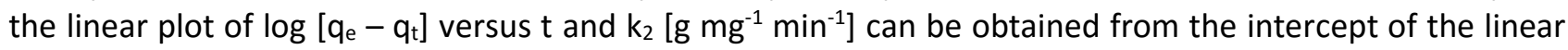


plot of $\mathrm{t} / \mathrm{q}_{\mathrm{t}}$ versus $\mathrm{t}$ (Ahlavanzadeh et al. 2010). The parameter of $\alpha$ [mg g. $\left.\mathrm{min}^{-1}\right]$ is the initial adsorption rate and $\beta\left[\mathrm{g} \mathrm{mg}^{-1}\right]$ is the rate desorption constant that can be calculated from the intercept and slope of the linear plot of $\mathrm{q}_{\mathrm{t}}$ versus $\mathrm{In} \mathrm{t}$ respectively, $\mathrm{k}_{\mathrm{d}}\left[\mathrm{mg} \mathrm{g}^{-1} \mathrm{~min}^{-1 / 2}\right]$ is the intra particle diffusion rate constant $\left[\mathrm{mg} \mathrm{g}^{-1} \mathrm{~min}^{-1 / 2}\right.$ ] that can be obtained from the slop of the linear plot $\mathrm{q}_{\mathrm{t}}$ versus $\mathrm{t}^{1 / 2}$ and $\mathrm{I}$ is a constant that gives idea about the thickness of the boundary layer.

\section{Results and disscusion}

\subsection{Characterization of $H M Z$}

The results of XRD analysis of $\mathrm{HMZ}$ are displayed in Fig. 1. The XRD diffraction pattern shows that clinoptilolite with the empirical formula $\left(\left(\mathrm{Al}_{6.59} \mathrm{Si}_{29} .41 \mathrm{O}_{72}\right) 28\left(\mathrm{H}_{2} \mathrm{O}\right) .\left(\mathrm{Na}_{0.52} \mathrm{~K}_{2}, 44 \mathrm{Ca}_{1.48}\right)\right)$ is $70 \%$ of sample. Other components are also found and identified as Ramsdellite (3\%), Silicon oxide (8\%), Potassium Aluminum Silicate (9\%). It indicates the $\mathrm{HMZ}$ is mainly composed of clinoptilolite.

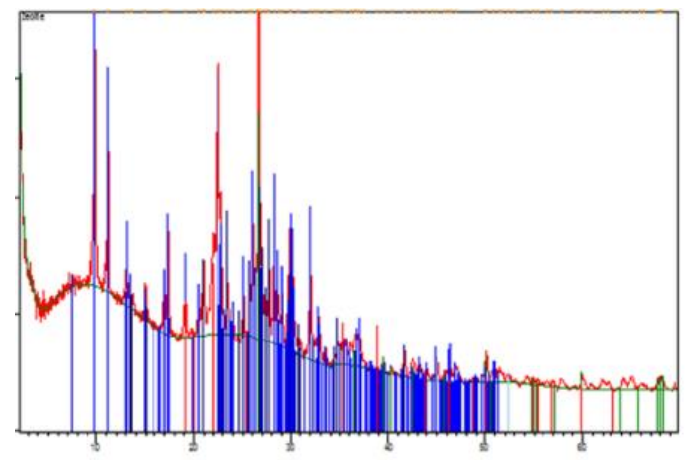

$2 \theta$

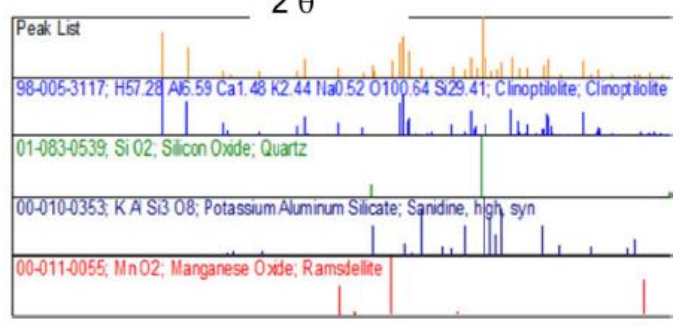

Figure 1. X-ray diffractogram of the HMZ sample

The hypermangan coated on zeolite surface is presented as ramsdellite (manganese (IV) oxide) with chemical formula of MnO2.The XRF analysis of the zeolite sample to determine the chemical compositions and characteristics of zeolite used in this study are expressed in Table 2. As is presented, the main components of natural zeolite of Semnan are, $\mathrm{SiO}_{2}$ and $\mathrm{Al}_{2} \mathrm{O}_{3}$. SEM images are very useful in obtaining adsorption details before and after coating.

Electron microscope images (SEM, AIS2300C, WD = 8.8) at $20 \mathrm{keV}$ ), for raw zeolite and HMZ are shown in Fig. 2. SEM study indicated that the structure of the zeolite changed as a result of coating, as zeolite surface sites were apparently occupied with hypermangan. Electron microscope images of $\mathrm{HMZ}$, represented a grow of hypermangan particles together on the surface of the zeolite and also shows the particles with much rougher surface as evidence of hypermangan particles coating. The FT-IR spectra of HMZ were used to determine the positions of different bands, their assignments and the functional groups in the adsorbent. Fig. 3 exhibits IR spectrums of $\mathrm{HMZ}$. 
Table 2. Semi-quantitative XRF analysis results of Semnan zeolite

\begin{tabular}{cc}
\hline Constituent & Percent \\
\hline $\mathrm{SiO}_{2}$ & 66.5 \\
\hline $\mathrm{Al}_{2} \mathrm{O}_{3}$ & 11.81 \\
\hline $\mathrm{Fe}_{2} \mathrm{O}_{3}$ & 1.3 \\
\hline $\mathrm{CaO}$ & 3.11 \\
\hline $\mathrm{MgO}$ & 0.72 \\
\hline $\mathrm{Na}_{2} \mathrm{O}$ & 2.01 \\
\hline $\mathrm{K}_{2} \mathrm{O}$ & 3.12 \\
\hline $\mathrm{P}_{2} \mathrm{O}_{5}$ & 0.01 \\
\hline $\mathrm{MnO}$ & 0.04 \\
\hline $\mathrm{TiO}_{2}$ & 0.21 \\
\hline $\mathrm{LOI}^{*}$ & 12.05 \\
\hline${ }^{*}$ Loss on ignition &
\end{tabular}

As shown in [Fig. 3], the peaks of at 3,450 and 1,633 cm-1 are due to bending vibration water molecules associated with $\mathrm{Na}$ and $\mathrm{Ca}$ in the channels of the zeolite. The bonds at 799 and $471 \mathrm{~cm}-1$ are attribute to the presence of $\mathrm{O}-\mathrm{T}-\mathrm{O}(\mathrm{T}=\mathrm{Si}$ and $\mathrm{Al}$ ) stretching vibration and the bending vibration mode of $\mathrm{T}-\mathrm{O}$, respectively. The peak of $1111 \mathrm{~cm}^{-1}$, is due to asymmetric stretching vibration mode of internal T-O bonds in $\mathrm{TO}_{4}$ tetrahedra. BET specific surface and total pore volume on the adsorbent were $2.14 \mathrm{~m}^{2} \mathrm{~g}^{-1}$ and 0.005 $\mathrm{cm}^{3} \mathrm{~g}^{-1}$, respectively. Because the specific surface area of $\mathrm{HMZ}$ is low, the functional groups likely have a more pronounced role than particle surface area in adsorbing nitrate from liquid. The mean pore diameter was calculated to be $0.64 \mathrm{~nm}$, indicating that $\mathrm{HMZ}$ is a micropore adsorbent.

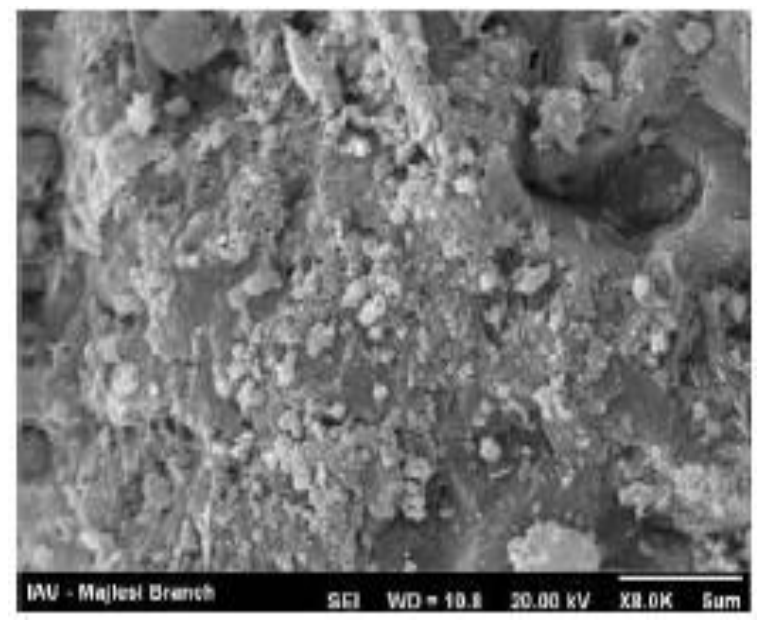

(a)

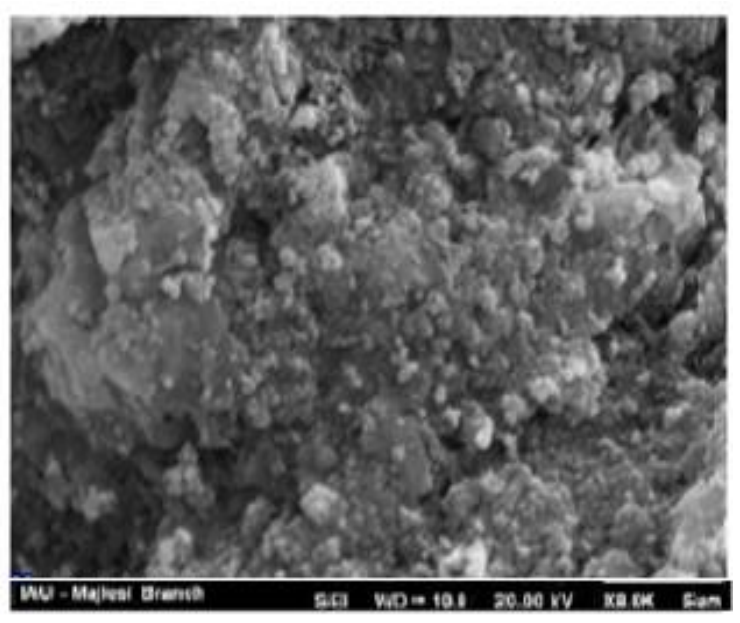

(b)

Figure 2. SEM images of (a) Raw zeolite, (b) HMZ 


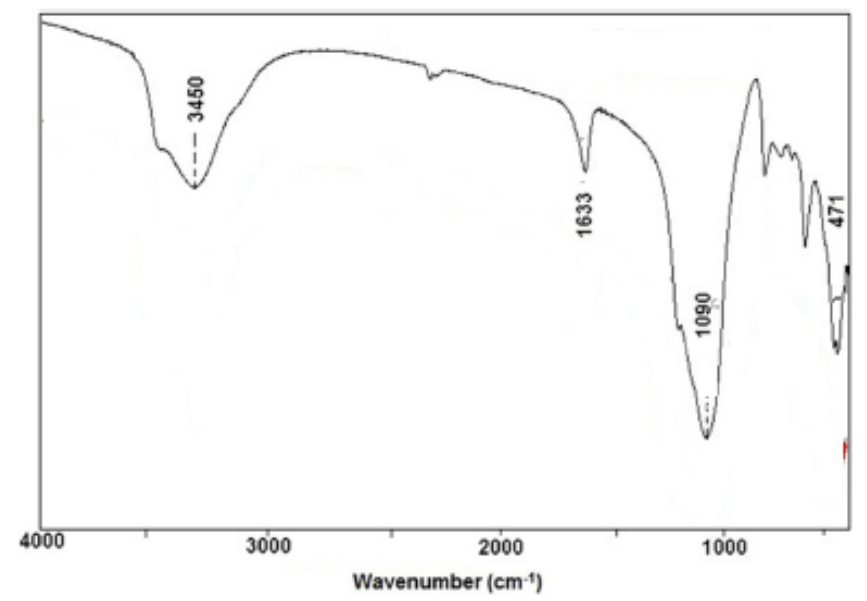

Figure 3. FTIR spectrum of HMZ adsorbent

\subsection{Effect of Initial $\mathrm{pH}$}

To determine the optimum solution $\mathrm{pH}, \mathrm{pH}$ was changed from 2-11 at an initial nitrate concentration of 150 $\mathrm{mg} \mathrm{l}^{-1}$ and an adsorbent dosage of $0.1 \mathrm{~g}$ of $\mathrm{HMZ}$ per $100 \mathrm{ml}$ of solution. As presented in Fig. 4, adsorption of nitrate onto $\mathrm{HMZ}$ varied with the initial $\mathrm{pH}$ of solution, so it is obvious that $\mathrm{pH}$ plays a significant role in the adsorption process. It may be due to $\mathrm{pH}$ influence on the surface properties of the adsorbent, surface charge of the adsorbent and ionization/dissociation of the adsorbate molecule.

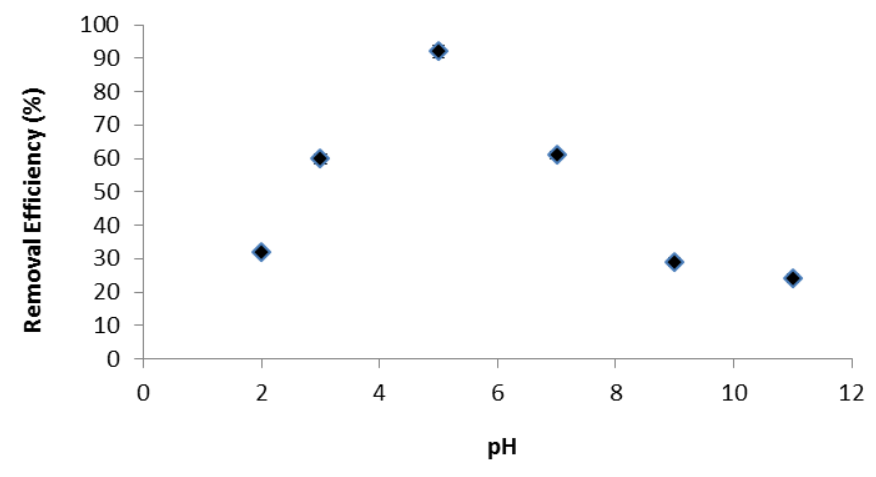

Figure 4. Effect of $\mathrm{pH}$ on the adsorption of nitrate onto $\mathrm{HMZ}$

$$
\left(\mathrm{C}_{0}=150 \mathrm{mg} \mathrm{L}^{-1}, \mathrm{t}=60 \mathrm{~min} ; \mathrm{HMZ} \text { dosage }=2 \mathrm{~g} \mathrm{~L}^{-1}, \mathrm{~T}=25^{\circ} \mathrm{C}\right) \text {. }
$$

The maximum removal efficiency of the $\mathrm{HMZ}$ was observed at a $\mathrm{pH}$ of 5.0. According to the researches carried out by other researchers the optimum $\mathrm{pH}$ is related to $\mathrm{pH}_{\mathrm{zpc}}\left(\mathrm{pH}_{\text {zero point charge }}\right)$ which at this $\mathrm{pH}$, surface charge is neutral and at $\mathrm{pH}$ levels lower than $\mathrm{pH}_{\mathrm{zpc}}$ surface charge is positive, while at $\mathrm{pH}$ levels higher than $\mathrm{pH}_{z \mathrm{pc}}$ surface charge is negative. Nitrate adsorption was found to increase with a decrease in the $\mathrm{pH}$ of the solution, because at $\mathrm{pH}$ levels with a positive charge, the anions of nitrate can be attracted to the surface of the HMZ having a negative surface charge and can increase the efficiency (decrease in the $\mathrm{pH}$ of the solution resulted in more protons being available to protonate the $\mathrm{HMZ}$ ) (Aguilar et al., 2005). In this study, the isoelectric point of the $\mathrm{HMZ}$ was determined to be $6.2\left(\mathrm{pH}_{\mathrm{zpc}}\right)$. At a pH levels below 6.2, the surface of the $\mathrm{HMZ}$ is positively 
charged that it resulted increased electrostatic interactions between negatively charged nitrate group and positively charged $\mathrm{HMZ}$ surface. With increasing $\mathrm{pH}$ to levels above $\mathrm{pH}_{\mathrm{zpc}}$, the number of negatively charged sites increase and the number of positively charged sites decrease. This does not favor the adsorption of anionic nitrate due to electrostatic repulsion. Furthermore, in an alkaline medium, a decrease in removal efficiency is due to the competition of $\mathrm{OH}^{-}$ions with anionic nitrate for adsorption onto the $\mathrm{HMZ}$. Yanhui et al., used cetylpyridinium bromide (CPB) modified zeolite as adsorbent for removal of nitrate from aqueous solution. They are presented that pH 6.0 is suitable for removal of nitrate by modified zeolite (Yanhui et al., 2011). In other research, Aghaii et al., used modified UZM-5 as adsorbent for nitrate removal from aqueous solution. It be seen that the adsorption of nitrate on adsorbent is clearly $\mathrm{pH}$ dependent. The maximum adsorption of nitrate was obtained at $\mathrm{pH} 7.0$ and in both acidic and alkaline range (3-5 and 9-11, respectively) the maximum amount of nitrate adsorption per mass of adsorbent was strongly reduced (Aghaii et al., 2013).

\subsection{Influence of $H M Z$ Dosage}

The mass of adsorbent can significantly affect adsorption efficiency due to increase in surface area and extension the greater number of exchangeable sites available for interaction with nitrate ions. The effect of $\mathrm{HMZ}$ dosage on nitrate removal was investigated at an optimum $\mathrm{pH}$ 5.0, under the conditions given in Table 1. As presented in Fig. 5, removal efficiency of nitrate increased with increasing HMZ dosage; as removal percentages of nitrate were obtained $48 \%$ and $92 \%$ for 0.1 and $2 \mathrm{~g} \mathrm{l}^{-1}$ of HMZ dosage, respectively. The removal efficiency remained almost unchanged thereafter. It is can be attributed to increase in surface area and available adsorption sites that resulted to high adsorption of nitrate ions onto HMZ. Achievement of a high nitrate removal percentage with a relatively low adsorbent dose indicates the high affinity and suitability of $\mathrm{HMZ}$ for removal of nitrate from wastewater.

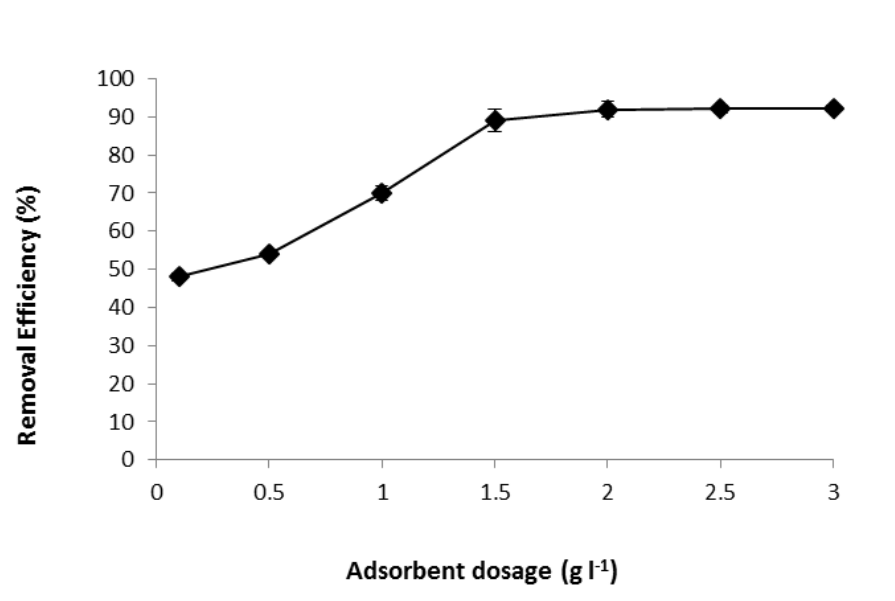

Figure 5. Influence of $\mathrm{HMZ}$ dose (0.1-2.5) on nitrate removal by $\mathrm{HMZ}\left(\mathrm{pH} 5.0, \mathrm{NO}_{3}^{-}=150 \mathrm{mgL}^{-1}\right.$, contact time $=60 \mathrm{~min}$ ).

\subsection{Equilibrium Adsorption Isotherm}

The equilibrium adsorption isotherm describes the relationship of the concentration of an adsorbate between two separate phases at equilibrium at a constant temperature, and this is an important step in finding a suitable model that can be used in the design of adsorption systems (Khorramfar et al., 2009).

The equation parameters of these models often characterize the adsorption mechanism, surface properties and affinity of the adsorbent. In this study, the adsorption of nitrate from its aqueous solution by HMZ was investigated with four of the most used isotherm models (Langmuir, Freundlich, Temkin and (D-R)). The values of related to Isotherm models are summarized in Table 3. 
Table 3. Isotherm parameters for nitrate adsorption onto HMZ

\begin{tabular}{cc}
\hline Langmuir & \\
\hline $\mathrm{q}_{\mathrm{m}}\left[\mathrm{mg} \mathrm{g}^{-1}\right]$ & 6.7 \\
\hline $\mathrm{b}\left[\mathrm{I} \mathrm{mg}^{-1}\right]$ & 1.42 \\
\hline $\mathrm{R}_{\mathrm{L}}$ & 0.04 \\
\hline $\mathrm{R}^{2}$ & 0.995 \\
\hline Freundlich & \\
\hline $\mathrm{K}_{\mathrm{F}}\left[\mathrm{mg} \mathrm{g}^{-1}\right]$ & 37.7 \\
\hline $\mathrm{n}$ & 0.22 \\
\hline $\mathrm{R}^{2}$ & 0.803 \\
\hline Temkin $^{-1}$ & 21.87 \\
\hline $\mathrm{B}\left[\mathrm{kJ} \mathrm{mol}^{-1}\right]$ & 1.47 \\
\hline $\mathrm{k}_{\mathrm{t}}\left[\mathrm{I} \mathrm{mg}^{-1}\right]$ & 0.832 \\
\hline $\mathrm{R}^{2}$ & \\
\hline $\mathrm{D}^{-R}$ & 7.5 \\
\hline $\mathrm{q}_{\mathrm{m}}\left[\mathrm{mg} \mathrm{g}^{-1}\right]$ & 21.87 \\
\hline $\mathrm{K}_{\mathrm{DR}}\left[\mathrm{mg}^{2} \mathrm{KJ}^{-1}\right]$ & 0.15 \\
\hline $\mathrm{E}\left[\mathrm{KJ} \mathrm{mg}^{-1}\right]$ & 0.954 \\
\hline $\mathrm{R}^{2}$ &
\end{tabular}

In the Langmuir isotherm model, it is assumed that all active sites have equal affinity for the sorbate, and this leads to monolayer coverage of the adsorbate at specific homogeneous sites on the outer surface of the adsorbent, therefore molecule or ion occupies the adsorption site, no further adsorption can take place. It is no dependency of molecule to the neighboring sites which is considered as monolayer adsorption. Maximum uptake capacity of unmodified zeolite was determined with the Langmuir model $\left(3.7 \mathrm{mg} \mathrm{g}^{-1}\right)$ and compared with the maximum uptake capacity of nitrate on the $\mathrm{HMZ}\left(6.7 \mathrm{mg} \mathrm{g}^{-1}\right)$, that it can be due to increase of active surfaces of modified adsorbent that it leads to increase of nitrate removal using permanganate modification. Yanhui et al. reached to maximum uptake capacity of 9.35 to 9.68 for different temperature, in removal of nitrate by modified zeolite with cetylpyridinium bromide (Yanhui et al., 2011). In research of Aghaii et al., the maximum monolayer sorption capacity of SMU for nitrate removal was found to be $18.62 \mathrm{mg} \mathrm{g}^{-1}$ at $298 \mathrm{~K}$ (Aghaii et al., 2013).

The value of $R_{L}$ describes the adsorption characteristics as follows:

$\mathrm{R}_{\mathrm{L}}=1$ linear.

$\mathrm{R}_{\mathrm{L}}=0$ irreversible.

$\mathrm{R}_{\mathrm{L}}>1$ unfavorable.

$0<\mathrm{R}_{\mathrm{L}}<1$ favorable.

Since the value of $R_{L}$ is between 0 and 1 , therefore adsorption of nitrate on $H M Z$ is favorable (because of $\left.\mathrm{R}_{\mathrm{L}}=0.04\right)$.

The Freundlich isotherm model is derived by assuming a heterogeneous surface. It is not limited to the formation of monolayer. This model is an empirical isotherm which describes non-ideal adsorption on heterogeneous surfaces and reversible adsorption. The $\mathrm{K}_{\mathrm{F}}$ value indicates the adsorption capacity of the adsorbent that with increasing it, adsorption capacity increases. The value of $\mathrm{n}$ for $\mathrm{HMZ}$ was between 0 and $1(0.22)$. This shows that nitrate adsorption onto $\mathrm{HMZ}$ is beneficial adsorption. 
Sudipta et al., in them research (removal of nitrate from aqueous solutions by chitosan hydrogel beads) said that $\mathrm{RL}$ value calculated using $\mathrm{C}_{0}=1000 \mathrm{mg} \mathrm{l}^{-1}$ is well within the defined range (0.07) and indicate the acceptability of the process (Sudipta et al., 2009).

$D-R$ isotherm determines a high degree of regularity, adsorption type and the mechanism.

The mean free energy of adsorption $[E]$ can be written as:

$$
\mathrm{E}=1 /\left[2 \mathrm{~K}_{\mathrm{DR}}\right]^{0.5}
$$

The amount of $E$ is used to determine the mechanism of the adsorption process. For instance, if the value of $\mathrm{E}$ is between 8 and $16 \mathrm{~kJ} \mathrm{~mol}^{-1}$, the adsorption process occurs through a chemical mechanism and if the value of $E$ is less than $8 \mathrm{~kJ} \mathrm{~mol}^{-1}$, the adsorption process occurs through a physical mechanism. For the adsorption of nitrate onto $\mathrm{HMZ}$, the value of $\mathrm{E}$ was $0.15 \mathrm{~kJ} \mathrm{~mol}^{-1}$, which indicates the adsorption of nitrate onto the $\mathrm{HMZ}$ occurs through a physical mechanism. Based on Table 2, values of the correlation coefficients $\left(R^{2}\right)$ were 0.995 , $0.803,0.832$ and 0.954 for Langmuir, Freundlich, Temkin and D-R models respectively. The high correlation coefficient value obtained from the Langmuir isotherm equation (0.995), indicates that the equilibrium data fit well with Langmuir model. It is the most common isotherm equation to use due to its simplicity and its ability to fit a variety of adsorption data. It is based on four assumptions:

1. All of the adsorption sites are equivalent and each site can only accommodate one molecule.

2. The surface is energetically homogeneous and adsorbed molecules do not interact.

3. There are no phase transitions.

4. At the maximum adsorption, only a monolayer is formed. Adsorption only occurs on localized sites on the surface, not with other adsorbents.

\subsection{Kinetic Study}

The effect of time on nitrate sorption efficiency was evaluated. As presented in Fig. 6, the time required to reach an equilibrium state was achieved in $60 \mathrm{~min}$. Therefore the shaking time was fixed in $60 \mathrm{~min}$. Adsorption is a surface phenomenon, that is related to surface area per unit weight and accessibility to pore of the adsorbent. Adsorption kinetics are important for evaluating the efficacy of adsorption and identify the adsorption mechanism. Kinetics of adsorption described chemical reaction rate and potential rate controlling steps. The kinetic behavior of this process was studied at pH 5.0 and $25{ }^{\circ} \mathrm{C}$ in shaking time 5 to $60 \mathrm{~min}$. The experimental data were fitted to four kinetics models including Pseudo-first order, Pseudo-second order, Elovich and Intra particle diffusion. The results of kinetic studies are shown in Table 4.

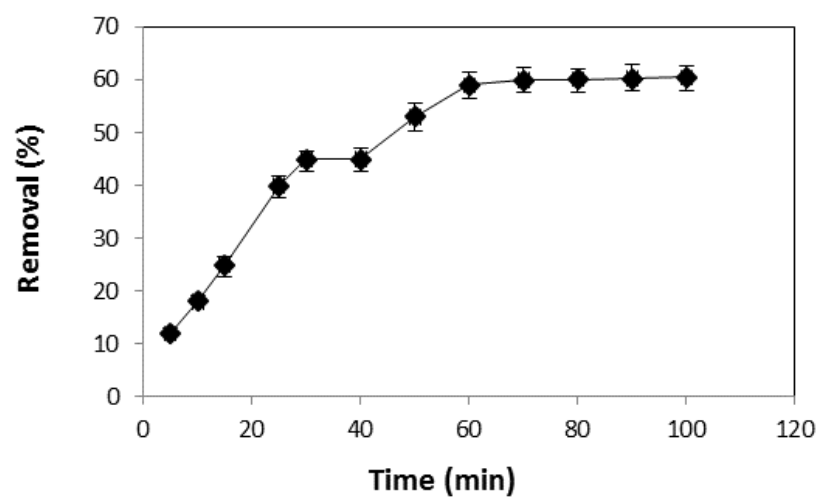

Figure 6. Effect of contact time on the adsorption of nitrate onto $\mathrm{HMZ}\left(\mathrm{C}_{0}=150 \mathrm{mg} \mathrm{l}^{-1}\right.$, $\mathrm{HMZ}$ dosage $=2 \mathrm{~g}^{-1}, \mathrm{~T}=25^{\circ} \mathrm{C}$ ) 
The parameters of kinetic models are presented in Table 4.The models were evaluated based on correlation coefficient, $\mathrm{R}^{2}$ and difference between the $\mathrm{q}_{\mathrm{e}}$ (theor) value with $\mathrm{q}_{\mathrm{e}}(\mathrm{exp})$. According to Table 4, the Pseudofirst-order kinetic model has higher correlation coefficient $\left(R^{2}=0.971\right)$ than the others as it is observed a little difference between $\mathrm{q}_{\mathrm{e}, \text { exp }}$ and $\mathrm{q}_{\mathrm{e}, \mathrm{cal}}$ and the $\mathrm{R}^{2}$ values are close to 1 .

Sudipta et al, in them research about removal of nitrate from aqueous solutions by chitosan hydrogel beads, said, the line for Pseudo-second-order model has higher correlation coefficients $(R 2=0.999)$ compared to the correlation coefficient $\left(R^{2}=0.988\right)$ obtained from the linear plot of the Pseudo-first-order rate model. (Sudipta et al., 2009).

The validity of the Pseudo-first and second order models was assessed by calculating the standard deviation between model-predicted and experimental adsorption capacities. As shown in Table 4 , the values of $\Delta q$ for all three concentrations were very low for the Pseudo-first order model in comparison to those for the Pseudo-second order model, confirming the applicability of the former. So, the adsorption behavior can be interpreted very well by this kinetic model over the whole range of contact time. The Intra particle diffusion model is to elucidate the diffusion mechanism. In many adsorption processes an Intra particle diffusion model, is the rate limiting step [if plot of $\mathrm{q}_{\mathrm{t}}$ versus $\mathrm{T}^{1 / 2}$ be straight line]. Also according to this model, if multi liner plots involve various steps, then two or more steps influence the adsorption process.

Table 4. Kinetic parameters for nitrate adsorption onto $\mathrm{HMZ}$

\begin{tabular}{|c|c|c|c|c|c|c|}
\hline $\mathrm{C}_{\mathrm{o}}[\mathrm{mg} \mathrm{L}-1]$ & & 100 & 150 & 200 & 250 & 300 \\
\hline$q e, \exp [m g g-1]$ & & 5.7 & 7.8 & 18 & 24 & 35 \\
\hline \multirow{4}{*}{ Pseudo-first- order } & qe, cal $\left[\mathrm{mg} \mathrm{g}^{-1}\right]$ & 4.3 & 7.29 & 16.5 & 22.8 & 33 \\
\hline & $\mathrm{k} 1$ [min-1] & 0.1 & 0.029 & 0.011 & 0.0005 & 0.0006 \\
\hline & $\mathrm{R}^{2}$ & 0.98 & 0.991 & 0.978 & 0.967 & 0.985 \\
\hline & $\Delta q(\%)$ & 2 & 1.2 & 2.2 & 2.4 & 2.1 \\
\hline \multirow{4}{*}{ Pseudo- second-order } & qe, cal $\left[\mathrm{mg} \mathrm{g}^{-1}\right]$ & 11.8 & 14.2 & 22.3 & 27 & 30.2 \\
\hline & k2 [g mg-1min-1] & 0.035 & 0.019 & 0.011 & 0.011 & 0.009 \\
\hline & $\mathrm{R}^{2}$ & 0.964 & 0.953 & 0.941 & 0.955 & 0.938 \\
\hline & $\Delta q(\%)$ & 48 & 46 & 40 & 35 & 50 \\
\hline \multirow{3}{*}{ Elovich } & $\alpha\left[\mathrm{mg} \mathrm{g}^{-1} \mathrm{~min}^{-1}\right]$ & 5.5 & 8.3 & 11 & 15 & 13.5 \\
\hline & $\beta\left[\mathrm{g} \mathrm{mg}^{-1}\right]$ & 7.2 & 6.5 & 5.5 & 4.5 & 3.5 \\
\hline & $\mathrm{R}^{2}$ & 0.921 & 0.964 & 0.923 & 0.954 & 0.968 \\
\hline \multirow{3}{*}{ Intra- particle diffusion } & $\mathrm{k}_{\mathrm{d}}\left[\mathrm{mgg}^{-1} \mathrm{~min}^{-1 / 2}\right]$ & 1.2 & 2.5 & 3.8 & 5.9 & 9.8 \\
\hline & $\mathrm{I}\left[\mathrm{mg} \mathrm{g}^{-1}\right]$ & 11.5 & 18.9 & 22.8 & 32.1 & 34.2 \\
\hline & $R^{2}$ & 0.889 & 0.927 & 0.954 & 0.925 & 0.948 \\
\hline
\end{tabular}

The kinetic data were analyzed by an Intra particle diffusion model, which often is the rate limiting step in many adsorption processes. In this model, if plot of $\mathrm{q}_{\mathrm{t}}$ versus $\mathrm{T}^{1 / 2}$ be straight line, the adsorption process is controlled by intra particle diffusion. Also according to Intra particle model, if multi linear plots involve various step, then two or more steps influence the adsorption process. The plot of $\mathrm{q}_{\mathrm{t}}$ versus $\mathrm{T}^{1 / 2}$ was straight line. The linearity of the plots illustrates that adsorption process may be controlled by Intra particle diffusion that indicates Intra particle diffusion involved in the nitrate adsorption onto $\mathrm{HMZ}$, but it is not the sole rate controlling step. 


\section{Conclusions}

In this study, the adsorption of nitrate onto $\mathrm{HMZ}$ adsorbent was investigated in equilibrium and kinetics. It was found that Langmuir isotherm model fitted best the equilibrium data and the maximum adsorption capacity $6.7 \mathrm{mg} \mathrm{g}^{-1}$ for nitrate was obtained. Also, the correlation coefficient greater than 0.97 indicated the applicability of Pseudo-first order adsorption model for nitrate adsorption onto $\mathrm{HMZ}$. The clinoptilolite is $70 \%$ of HMZ. Intra particle diffusion is sole rate controlling factor and the process may be controlled by intra particle diffusion. The investigation shows favorable adsorption site for nitrate on the surface of $\mathrm{HMZ}$ adsorption and shows that $\mathrm{HMZ}$ is a promising adsorbent for the removal of nitrate from aqueous solution.

\section{References}

Aghaii M.D., Pakizeh M. and Ahmadpour A. (2013), Synthesis and characterization of modified UZM-5 as adsorbent for nitrate removal from aqueous solution, Separation and Purification Technology, 113, 24-32.

Aguilar M.I., Saes J., Lorene M., Solar A., Ortuno J.F., Meseguer V. and Fuentes A. (2005), Improvement of coagulationflocculation process using anionic polyacrylamide as coagulant aid, Chemosphere, 58, 47-56.

Al Ghouti M.A., Al Degs Y.S., Khraisheh M.A.M., Ahmad M.N. and Allen S.J. (2009), Mechanisms and chemistry of dye adsorption on manganese oxides-modified diatomite, J. Environ. Manag., 90, 3520-3527.

Andalib M., Nakhla G.and Zhu J. (2012), High-rate biological nutrient removal from high-strength wastewater using anaerobic-circulating fluidized bed bioreactor (A-CFBBR) ,Bioresour. Technol, 118, 526-535.

APHA, (2005). Standard Methods for the Examination of Water and Wastewater, 21td Ed, American Public Health Association, Washington.

Benyoucef N., Cheikh A., Drouiche N., Lounici H., Mameri N. and Abdi N. (2013), Denitrification of groundwater using Brewer's spent grain as biofilter media, Ecol. Eng, 52, 70-74.

Bravo R., Segovia E., Guerrero L., Montalvo S.,Barahona A. and Borja R. (2013), Total ammoniacal nitrogen biofiltration of wastewaters from aquaculture systems using Macrocystis spp, J. Environ. Sci. Health, 48, 400-407.

Cheikh A., Yala A., Drouiche N., Abdi N., Lounici H. and Mameri N. (2013), Denitrification of water in packed beds using bacterial biomass immobilized on waste plastics as supports, Ecol. Eng, 53, 329-334.

Dong L., Zhu Z., Ma H., Qiu Y. and Zhao J. (2010), Simultaneous sorption of lead and cadmium on $\mathrm{MnO}_{2}$-loaded resin, J. Environ. Sci, 22, 225-229.

Gupta V.K., Agarwal S. and Saleh T.A. (2011), Synthesis and characterization of alumina-coated carbon nanotubes and their application for lead removal, J. Hazard. Mater, 185, 17-23.

Gupta S.S. and Bhattacharyya K.G. (2008), Immobilization of Pb(II), Cd(II) and $\mathrm{Ni}(\mathrm{II})$ ions on kaolinite and ontmorillonite surfaces from aqueous medium, J. Environ. Manag, 87, 46-58.

Jiang T., Zhang H., Qiang H., Yang F., Xu X. and Du H. (2013), Start-up of the anammox process and membrane fouling analysis in a novel rotating membrane bioreactor, Desalination, 311, 46-53.

Hajdu I., Bodnár M., Csikós Z., Wei S., Daróczi L., Kovács B., Győri Z., Tamás J. and Borbély J. (2012), Combined nanomembrane technology for removal of lead ions, J. Membr. Sci, 409, 44-53.

Han R.H., Zou W., Zhang Z.P., Shi J. and Yang J.J. (2006), Removal of copper(II) and lead(II) from aqueous solution by manganese oxide coated sand: I. Characterization and kinetic study, J. Hazard. Mater, 137, 384-395.

Han R.P., Zou W.H., Li H.K., Li Y.H. and Shi J. (2006), Copper(II) and lead(II) removal from aqueous solution in fixed-bed columns by manganese oxide coated zeolite, J. Hazard. Mater, 137, 934-942.

Khorramfar S., Mahmoodi N.M., Arami M. and Gharanjig K. (2009), Dye Removal from Colored Textile Wastewater Using TamarindusIndica Hull: Isotherm and Kinetics Study, Journal of Color Science Technology, 3, 81-88.

Malekian R., Abedi-Koupai J., Eslamian S.S., Mousavi S.F., Abbaspour K.C. and Afyuni M. (2011), lon-exchange process for ammonium removal and release using natural Iranian zeolite, Appl. Clay Sci, 51, 323-329. 
Montalvo S., Olivares P., Guerrero L. and Borja R. (2011), Nitrogen and phosphorus removal using a novel integrated system of natural zeolite and lime, J. Environ. Sci. Health, 47, 1385-1391.

Ngah W.W. and Hanafiah M.(2008), Adsorption of copper on rubber (Hevea brasiliensis) leaf powder: Kinetic, equilibrium and thermodynamic studies, Biochemical Engineering Journal, 39, 521-530.

Rezakazemi M., Shirazian S. and Ashrafizadeh S.N. (2012), Simulation of ammonia removal from industrial wastewater streams by means of a hollow-fiber mem- brane contactor, Desalination, 285, 383-392.

Sudipta C. and Seung H. W. (2009), The removal of nitrate from aqueous solutions by chitosan hydrogel beads, Journal of Hazardous Materials, 164, 1012-1018

Yanhui Z., Jianwei L. and Zhiliang Z. (2011), Removal of nitrate from aqueous solution using cetylpyridinium bromide (CPB) modified zeolite as adsorbent, Journal of Hazardous Materials, 186, 1972-1978

Yu R., Geng J., Ren H., Wang Y. and Xu K. (2013), Struvite pyrolysate recycling combined with dry pyrolysis for ammonium removal from wastewater, Bioresour. Technol, 132, 154-159.

Zhang T., Ding L., Ren H. and Xiong X. (2009, Ammonium nitrogen removal from coking wastewater by chemical precipitation recycle technology, Water Res., 43, 5209-5215.

Zou W., Han R., Chen Z., Jinghua Z. and Shi J. (2006), Kinetic study of adsorption of Cu(II) and Pb(II) from aqueous solutions using manganese oxide coated zeolite in batch mode, Colloids and Surfaces A: Physicochemical and Engineering Aspects, 279, 238-246. 